\title{
Effect of Hydrohalogenation of PtRe/H-ZSM-5 for Cyclohexene Conversion
}

\author{
Sameh M. K. ABOUL-FOTOUH ${ }^{1,{ }^{*},}$, Noha A. K. ABOUL-GHEIT ${ }^{2}$ \\ ${ }^{1}$ Chemistry Department, Faculty of Education, Ain-Shams University, Cairo 11757, Egypt \\ ${ }^{2}$ Process Development Department, Egyptian Petroleum Research Institute, Cairo 11787, Egypt
}

\begin{abstract}
Extended use of supported Pt catalysts causes thermal migration of Pt particles to form large agglomerates, thus decreasing the catalytic activity. The combination of $\mathrm{Pt}$ with Re protects $\mathrm{Pt}$ against migration. In addition, $\mathrm{Cl}^{-}$injection into the reactor assists $\mathrm{Pt}$ particles redispersion to prolong catalyst life. In this work, a PtRe/H-ZSM-5 catalyst was treated with either $\mathrm{HCl}$ or HF to investigate their role in activating or deactivating the catalyst. The conversion exceeded $90 \%$ in the whole temperature range with the PtRe/H-ZSM-5(HCl) catalyst, and its activity for the direct isomerization of cyclohexene to methylcyclopentenes (MCPEs) was the lowest but the activity for the hydrogenation of the MCPEs to methylcyclopentane was the highest. The reactivities of MCPEs and cyclohexadienes on the catalysts were similar because both are dehydrogenation reactions. Benzene production was significantly higher on the hydrochlorinated catalyst than on the other catalysts, and its hydrocracking activity was the lowest, which is a good characteristic for processing catalysts where cracking is undesired.
\end{abstract}

Key words: platinum; rhenium; cyclohexene; hydroconversion; hydrofluorination; hydrochlorination; H-ZSM-5 zeolite

CLC number: O643 Document code: A

Received 31 October 2011. Accepted 13 February 2012.

*Corresponding author.Tel: +202-227-57840; Fax:+202-225-81243; E-mail: saboulfotouh@hotmail.com

English edition available online at Elsevier ScienceDirect (http://www.sciencedirect.com/science/journal/18722067).

Cyclohexene (CHE) conversion on bifunctional catalysts goes through a number of reactions that each requires a different active site type. Hence, CHE is frequently selected as a probe molecule for characterizing catalyst preparation [1-4]. The experimental conditions, temperature and presence or absence of hydrogen and the pressure of hydrogen, have important effects on the catalytic behavior. In the absence of hydrogen, disproportionation $[5,6]$ and dehydrogenation $[7,8]$ reactions take place. The former reaction gives benzene and cyclohexane (CHA) and the reaction is hydrogen transfer. When the reaction is carried out in the presence of metal catalysts, CHE behaves as both hydrogen donor and acceptor. If the metal is supported on $\mathrm{Al}_{2} \mathrm{O}_{3}$ [9], the acid sites are weakly Lewis acid and not strong enough to promote carbonium ion formation, and hence isomerization and cracking reactions do not occur (monofunctional catalyst). The use of the H-form of zeolites, which possess strongly acidic Brönsted and Lewis sites, can promote CHE isomerization to a mixture of methylcyclopentenes (MCPEs) and cracking to lower molecular mass hydrocarbons and the reaction scheme is more complicated (bifunctional catalyst). However, the treatment of the cation-exchanged zeolites with aqueous $\mathrm{HCl}$ or $\mathrm{HF}$ acid leads to loss of cations and partial dealumination of the zeolite framework.

Isomerization of CHE over very pure alumina with and without $\mathrm{Cl}^{-}$ions has been studied by Ozimek et al. [10,11].
Introducing $\mathrm{Cl}^{-}$ions into aluminate aluminas in different ways causes Brönsted acid sites to appear, and both skeletal isomerzation and total conversions were much increased [12].

CHE hydrogenation and dehydrogenation are much faster than benzene hydrogenation and CHA dehydrogenation on noble metal catalysts. Aboul-Gheit and coworkers have studied aromatic hydrogenation [13], hydroconversion of $n$-paraffins in light naphtha [14], cyclohexane dehydrogenation [15] and hydroisomerization, hydrocracking and dehydrocyclization of $n$-paraffins $[14,16]$ using $\mathrm{Pt} / \mathrm{Al}_{2} \mathrm{O}_{3}$ catalysts promoted with other metals ( $\mathrm{Rh}, \mathrm{Ir}, \mathrm{Re}$ or $\mathrm{U}$ ) and $\mathrm{Cl}^{-}$ or $\mathrm{F}^{-}$. Rhenium is a promoter for platinum in catalysts for petroleum naphtha hydroisomerization and reforming used for upgrading octane numbers. Although Pt-Re catalysts have received enormous attention since the discovery of the Re promotion effect by Kluksdahl [17], monometallic Re catalysts have not received much consideration. Researches on Pt promoted by Re were mainly concerned with catalyst protection to extend its lifetime. However, these catalysts are also conventionally treated with injected light chlorohydrocarbons to generate $\mathrm{HCl}$, which improves catalyst acidity and Pt dispersion. Since Kluksdahl [17] showed that Re addition to platinum is required to give superior petroleum naphtha reforming catalysts, the most commercially successful bimetallic catalysts used in refineries contain Pt-Re 
combinations [18-20].

CHE hydrogenation and dehydrogenation have been investigated using $\mathrm{Ni}, \mathrm{Pt}, \mathrm{Rh}$, and $\mathrm{Pd}$ catalysts $[6,8,21-28]$. CHE hydroconversion over catalysts containing $0.35 \mathrm{wt} \%$ of the single metals Rh, Pt, Ir, Re, and their combinations on $\gamma-\mathrm{Al}_{2} \mathrm{O}_{3}$ was carried out at temperatures of $50-250{ }^{\circ} \mathrm{C}$ [9]. The effect of doping with $3.0 \mathrm{wt} \%$ of $\mathrm{Cl}^{-}$or $\mathrm{F}^{-}$was examined. The bimetallic combinations gave more active catalysts than the monometallic catalysts. In the present work, a Pt-Re loaded H-ZSM-5 catalyst was treated with $3.0 \% \mathrm{HCl}$ or $\mathrm{HF}$ to examine their effects on CHE hydroconversion in a flow reactor operated in presence of hydrogen at $50-400{ }^{\circ} \mathrm{C}$.

\section{Experimental}

\subsection{Catalyst preparation}

\subsubsection{H-ZSM-5 catalyst}

This catalyst was prepared by exchanging Na-ZSM-5 zeolite with $0.6 \mathrm{~mol} / \mathrm{g} \mathrm{NH}_{4} \mathrm{NO}_{3}$ solution followed by drying at $110{ }^{\circ} \mathrm{C}$ overnight and calcination at $550{ }^{\circ} \mathrm{C}$ for $4 \mathrm{~h}$. The Na-zeolite was provided by Süd Chemie, München, Germany. The catalyst had a Si/Al molar ratio of 23.8, specific surface area of $440 \mathrm{~m}^{2} / \mathrm{g}$, and pore volume of $0.16 \mathrm{~cm}^{3} / \mathrm{g}$. The H-form had a sodium content $<0.002 \%$.

\subsubsection{PtRe/H-ZSM-5 catalyst}

The PtRe/H-ZSM-5 catalyst was prepared by two successive impregnations: first with an aqueous solution of hexachloroplatinic acid followed by a second impregnation with ammonium perrhenate to give $0.35 \mathrm{wt} \% \mathrm{Pt}+0.35 \mathrm{wt} \% \mathrm{Re}$ in the finished catalyst. The catalyst was dried and calcined as in Section 1.1.1 after each impregnation. It was reduced in a hydrogen flow in the catalytic reactor at $500{ }^{\circ} \mathrm{C}$ for $8 \mathrm{~h}$ before the reaction.

\subsubsection{PtRe/H-ZSM-5(HCl) catalyst}

The PtRe/H-ZSM-5 catalyst prepared in section 1.1.2 was doped with a solution containing the required quantity of $\mathrm{HCl}$ acid to give $3.0 \% \mathrm{HCl}$. The catalyst was then dried, calcined, and reduced as above.

\subsubsection{PtRe/H-ZSM-5(HF) catalyst}

The PtRe/H-ZSM-5 catalyst prepared in section 1.1.2 was doped with HF solution sufficient to give $3.0 \%$ HF. It was dried, calcined, and then reduced as above.

All the catalysts basically retained the crystallinity of the original H-ZSM-5 zeolite, which was shown by X-ray dif- fraction (XRD) analysis. The main diffraction peak in all forms appeared at $2 \theta$ of $23.0^{\circ}$. However, a very slight increase in the diffraction peak at $2 \theta$ of $10.884^{\circ}$ for the $\mathrm{PtRe} / \mathrm{H}-\mathrm{ZSM}-5(\mathrm{HCl})$ and PtRe/H-ZSM-5(HF) catalysts indicated a slight bulk dealumination of the H-ZSM-5 zeolite.

\subsection{Hydroconversion reactor and product analysis}

The reactor was a silica glass tube containing $0.2 \mathrm{~g}$ catalyst heated in an insulated wider silica tube jacket thermostated to $\pm 1{ }^{\circ} \mathrm{C}$. Hydrogen gas was used as a carrier and simultaneously as a reactant at a flow rate of $20 \mathrm{ml} / \mathrm{min}$ in all runs. The feed (CHE) was introduced into the reactor using a $\mathrm{H}_{2}$ flow passed into a closed jar thermostated at a fixed temperature of $28{ }^{\circ} \mathrm{C}$ whereby the quantity of cyclohexene fed to the catalyst was $8.33 \times 10^{-3} \mathrm{~mol} / \mathrm{h}$, i.e., the $\mathrm{H}_{2} / \mathrm{CHE}$ molar ratio was 6.4 in all runs. The amount of CHE condensed between saturator and reactor was considered in calculating the actual mass of CHE flowing over the catalyst. The reaction temperatures were $50-400{ }^{\circ} \mathrm{C}$, at $25{ }^{\circ} \mathrm{C}$ decrements starting from $400{ }^{\circ} \mathrm{C}$ downwards. The gaseous reaction effluent from the reactor was injected into a Perkin-Elmer Autosystem XL gas chromatograph with a 15 $\mathrm{m}$ capillary column of Carbowax $20 \mathrm{M}$ bonded in fused silica and analyzed using a FID detector and a Turbochrom Navigator program. The GC column separated the product effluent into hydrocracked components, MCPEs, methylcyclopentane (MCPA), CHE, CHA, cyclohexadienes (CHDEs) (1,3- and 1,4-), and aromatics (benzene, toluene, and xylenes). The examination after a time on-stream of $180 \mathrm{~min}$ at $400{ }^{\circ} \mathrm{C}$ did not show any decrease in the activity of the catalyst. Moreover, examination of the catalysts for carbon deposition using temperature-programmed oxidation (TPO) in a differential scanning calorimeter (DSC) did not show any $\mathrm{CO}_{2}$ peak.

\subsection{Catalyst characterization}

The temperature-programmed desorption (TPD) of presorbed ammonia on the acid sites of the zeolite supports was carried out in a DSC using nitrogen as a purge gas according to the procedure previously reported $[29,30]$. The $\mathrm{NH}_{3}$ desorption enthalpy values from the higher temperature endothermic peak was used to correlate the acid site density of the three PtRe/H-ZSM-5 catalysts. The peak temperature was used to correlate the strength of these acid sites.

The dispersion of PtRe in the catalysts (metal fraction exposed) was determined by hydrogen chemisorption using a pulse technique similar to that used by Freel [31]. A known mass of a calcined catalyst was heated in the chemisorption furnace at $500{ }^{\circ} \mathrm{C}$ for $3 \mathrm{~h}$ in a flow of $50 \mathrm{ml} / \mathrm{min}$ of 
ultra-pure hydrogen. The flow was then replaced by oxygen-free nitrogen gas at $30 \mathrm{ml} / \mathrm{min}$ for $2 \mathrm{~h}$ at $500{ }^{\circ} \mathrm{C}$ (degassing). The furnace was shut off and the catalyst was cooled to room temperature. Hydrogen was then pulsed into the nitrogen carrier till saturation, i.e., until the appearance of hydrogen peaks corresponding to complete non-adsorbed pulses. The hydrogen uptake was calculated as hydrogen atoms adsorbed per total Pt-Re atoms on the basis of $1: 1$ stoichiometry.

The X-ray diffraction (XRD) patterns of the catalysts were carried out using a Phillips X, Pert Diffractometer PW 1390 at $40 \mathrm{kV}$ and $30 \mathrm{~mA}$ with $\mathrm{Ni}$ Filter and $\mathrm{Cu} K_{\alpha}$ radiation. The XRD measurements were carried out up to $2 \theta$ of $60^{\circ}$. The XRD patterns obtained (not given here) for the catalysts showed fairly similar intensities for the diffraction peaks. The main crystalline peak appeared in all samples at $2 \theta$ of $23.0^{\circ}$. The $\mathrm{HCl}$ and $\mathrm{HF}$ doped samples showed slightly higher relative intensity of the lowest $2 \theta$ peak, indicating slight dealumination of the zeolite support.

\section{Results and discussion}

Light organic chlorohydrocarbons are normally injected into the industrial reactors used in the light naphtha hydroisomerization process. This procedure is applied for the catalyst chlorination with commercial $\mathrm{Pt} / \mathrm{Al}_{2} \mathrm{O}_{3}$ catalysts since these chlorohydrocarbons produce $\mathrm{HCl}$ and small hydrocarbons at higher temperatures. The $\mathrm{HCl}$ formed assists the redistribution of the platinum crystallites and inhibits their growth into agglomerates, besides enhancing the acidity of the catalyst. This treatment differs from that normally applied in preparing chlorinated $\mathrm{Pt} /$ zeolite catalysts where the support is first halogenated before impregnating or exchanging with a Pt precursor. The use of the hydrofluorination of noble metal-containing catalysts may be an alternative for $\mathrm{HCl}$ doping because the $\mathrm{Al}-\mathrm{F}$ bond is stronger than the $\mathrm{Al}-\mathrm{Cl}$ bond and the requirement for the continuous injection of a fluorohydrocarbon into the reactor is therefore unnecessary.

The metal mainly used in light naphtha hydroisomerization and heavy naphtha reforming catalysts is platinum. However, another metal such as $\mathrm{Ir}, \mathrm{Re}, \mathrm{Pd}$, Ti or $\mathrm{Sn}$ is normally combined with $\mathrm{Pt}$ in the catalyst, mainly to improve the catalyst lifetime by restricting Pt agglomeration, sulphur poisoning and deactivation by carbon deposition. It is important to know the behavior of the promoter metal towards the presence or absence of $\mathrm{HCl}$ or $\mathrm{HF}$ when the metal is supported on H-ZSM-5 zeolite. In the present work, the doping of PtRe/H-ZSM-5 catalysts with $\mathrm{HCl}$ or $\mathrm{HF}$ was investigated with the hydroconversion of $\mathrm{CHE}$.

\subsection{Effect of hydrochlorination or hydrofluorination}

\section{on the PtRe/H-ZSM-5 catalyst}

With 3.0\% $\mathrm{HCl}$ doping, the acid site density (Table 1) was enhanced $\left(\Delta H_{\mathrm{d}}=96.0 \mathrm{~J} / \mathrm{g}\right)$ over that of the untreated catalyst $\left(\Delta H_{\mathrm{d}}=90.9 \mathrm{~J} / \mathrm{g}\right)$. Hydrofluorination gave a lower density of acid sites $\left(\Delta H_{\mathrm{d}}=94.2 \mathrm{~J} / \mathrm{g}\right)$ than hydrochlorination. However, the effect of hydrofluorination was higher than hydrochlorination for enhancing the strength of the acid sites, with the ammonia desorption peak temperature being in the order of PtRe/H-ZSM-5(HF) > PtRe/H-ZSM-5 $(\mathrm{HCl})>$ PtRe/H-ZSM-5.

Table $1 \mathrm{NH}_{3}-\mathrm{TPD}$, and $\mathrm{Re}$ and Pt-Re dispersion by $\mathrm{H}_{2}$ chemisorption in the Re/H-ZSM-5 and PtRe/H-ZSM-5 catalyst

\begin{tabular}{|c|c|c|c|}
\hline \multirow[b]{2}{*}{ Catalyst } & \multicolumn{3}{|c|}{ Acid site strength distribution } \\
\hline & $\Delta H^{\mathrm{a}} /(\mathrm{J} / \mathrm{g})$ & $\begin{array}{c}\text { Peak temperature }^{\mathrm{b}} \\
\left({ }^{\circ} \mathrm{C}\right)\end{array}$ & $\begin{array}{c}\text { Metal } \\
\text { dispersion (\%) }\end{array}$ \\
\hline $\mathrm{Re} / \mathrm{H}-\mathrm{ZSM}-5^{\mathrm{c}}$ & 90.9 & 380.1 & 56.8 \\
\hline $\mathrm{Re} / \mathrm{H}-\mathrm{ZSM}-5(\mathrm{HCl})^{\mathrm{c}}$ & 99.6 & 392.3 & 59.8 \\
\hline $\mathrm{Re} / \mathrm{H}-\mathrm{ZSM}-5(\mathrm{HF})^{\mathrm{c}}$ & 105.3 & 415.7 & 63.8 \\
\hline PtRe/H-ZSM-5 & 90.9 & 376.1 & 58.8 \\
\hline PtRe/H-ZSM-5(HCl) & 96.0 & 390.3 & 63.5 \\
\hline PtRe/H-ZSM-5(HF) & 94.2 & 395.9 & 60.8 \\
\hline
\end{tabular}

${ }^{\text {a }}$ Proportional to acid site number.

${ }^{\mathrm{b}}$ Proportional to acid site strength.

${ }^{\mathrm{c}}$ Reference 32 .

Treating PtRe/H-ZSM-5 with the acids affected Pt-Re dispersion (Table 1). With the $\mathrm{HCl}$ treatment, the metal dispersion was increased over that using the HF treatment. The dispersion order was PtRe/H-ZSM-5 $(\mathrm{HCl})>\mathrm{PtRe} /$ H-ZSM-5(HF) > PtRe/H-ZSM-5.

The comparison of the properties of the Re/H-ZSM-5 [32] and PtRe/H-ZSM-5 catalysts (Table 1) before and after $\mathrm{HCl}$ or $\mathrm{HF}$ treatments indicated that dispersion of either mono-metal ( $\mathrm{Re})$ or bimetal (Pt-Re) in the H-ZSM-5 support was increased after halogenation. Also, the acid site number $\left(\Delta H_{\mathrm{d}}\right)$ and strength $\left(\mathrm{NH}_{3}\right.$ peak temperature) were increased by this treatment. Hydrofluorination was significantly more effective than hydrochlorination when the catalyst contained Re alone. In case of the PtRe/H-ZSM-5 catalyst, the HF-treated case was less significantly affected than the HCl-treated version for both metals dispersion and acidic properties. Since $\mathrm{HF}$ is a stronger acid than $\mathrm{HCl}$, it can be assumed that the combination of $\mathrm{Pt}$ and $\mathrm{Re}$ is not as good for metal dispersion and acidity than when Re was loaded alone in the zeolite. Pt when present with Re seems to have played a role in diminishing the spreading of the metal on the surface of the zeolite as well as blocking of the acid sites. This can be attributed to that the deposition of fluoro-silicon and fluoro-aluminum debris was more than that of chloro-aluminum debris.

In our recent work [33], pore volume distribution curves 
for catalysts containing 2\% Pt/H-ZSM-5 before and after doping with $4 \% \mathrm{HF}$ for the alkylation of toluene with methanol were shown. In the catalyst treated with $4 \% \mathrm{HF}$, the large pores in the volume distribution curve (in the range of 2.7-5.5 $\mathrm{nm}$ ) had lower values than those of the untreated catalyst, while the smaller pores $(0.3-2.7 \mathrm{~nm})$ has higher values. This was attributed to the filling of most of the large pores by the debris formed from the leaching of $\mathrm{Al}$ and $\mathrm{Si}$ at $4 \% \mathrm{HF}$ concentration.

\subsection{Effect of HCl or HF doping of PtRe/H-ZSM-5 catalyst on the conversion of cyclohexene}

The distribution of the $\mathrm{CHE}$ hydroconversion products using the PtRe/H-ZSM-5, PtRe/H-ZSM-5(HCl) and PtRe/H-ZSM-5(HF) catalysts are shown in Fig. 1. The general features are a continuous decrease of $\mathrm{CHE}$ with reaction temperature and an increase of $\mathrm{CHA}$ at $50-200{ }^{\circ} \mathrm{C}$. At intermediate temperatures, MCPEs, and MCPA passed through maxima at $300-325{ }^{\circ} \mathrm{C}$, beyond which they de-

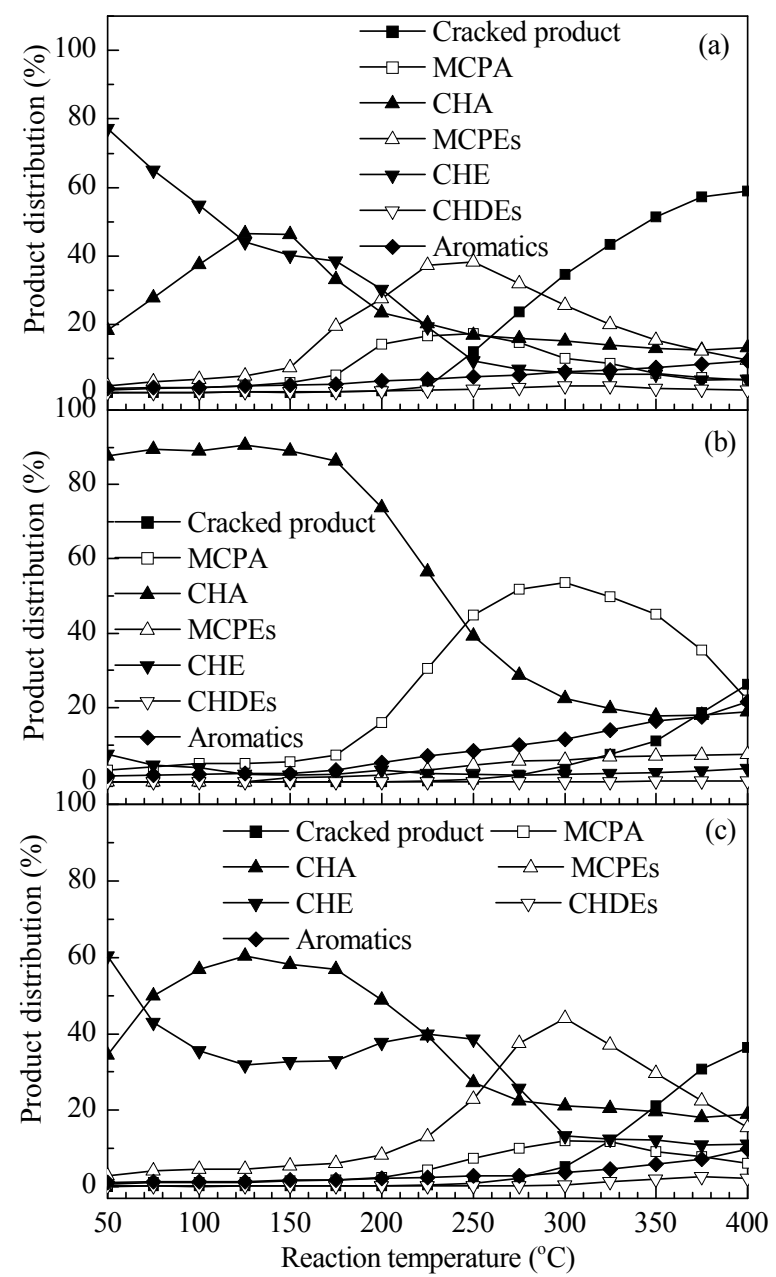

Fig. 1. Distribution of cyclohexene hydroconversion product with PtRe/H-ZSM-5 (a), PtRe/H-ZSM-5(HCl) (b), and PtRe/H-ZSM-5(HF) (c). creased. At higher temperatures, CHE dehydrogenation to aromatics via CHDE formation and hydrocracking to lower molecular mass hydrocarbons increased continuously with temperature.

Figure 1(b) exhibited a distinct variation where the MCPEs comprises $\sim 90 \%$ of the product between 50 and 175 ${ }^{\circ} \mathrm{C}$, beyond which these cycloolefins decline to $<20 \%$ at $400{ }^{\circ} \mathrm{C}$. Another major product was MCPA, the hydrogenation product of MCPEs, which reached a maximum of $\sim 50 \%$ at $300{ }^{\circ} \mathrm{C}$ beyond which it declined to $\sim 20 \%$ at 400 ${ }^{\circ} \mathrm{C}$. All other intermediates were generally less.

Figure 2 compares the CHE hydroconversion activities of the PtRe-containing catalysts as a function of reaction temperature. The highest activity was given by the $\mathrm{HCl}$ treated catalyst in the whole reaction temperature range of 50-400 ${ }^{\circ} \mathrm{C}$. The lowest activity was given by the untreated catalyst at low reaction temperatures. However, at $200-400{ }^{\circ} \mathrm{C}$, the $\mathrm{HF}$ treated catalyst became the least active.

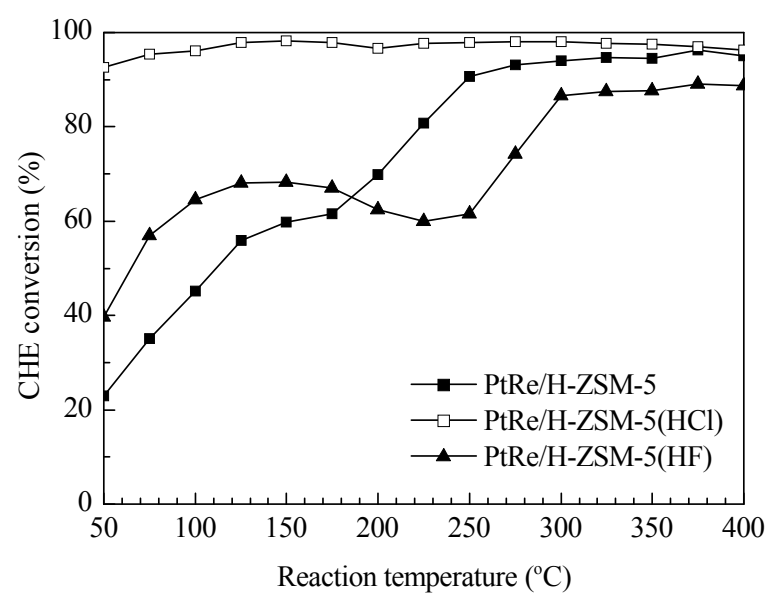

Fig. 2. Hydroconversion of cyclohexene using different catalysts.

\subsection{Hydrogenation of CHE to CHA}

CHE is an unsaturated hydrocarbon molecule, and its initial adsorption is largely through the most energetically favorable donor $\pi$ and acceptor $\pi^{*}$ orbitals with the appropriate metal surface orbitals. On an atomically flat surface, CHE can form a chemisorption state in which the $\mathrm{C}_{6}$-ring is oriented in a plane parallel to the surface plane. The first reaction of chemisorbed $\mathrm{CHE}$, taking place at low reaction temperatures, is its exothermic hydrogenation to CHA. Thus, the hydroconversion activity of CHE (Fig. 2) can be attributed mainly to its hydrogenation to CHA (Fig. 3) throughout the low temperature range $\left(50-200{ }^{\circ} \mathrm{C}\right)$. The activities of the catalysts are in the order of PtRe/H-ZSM-5(HCl) > PtRe/H-ZSM-5(HF) > PtRe/H-ZSM-5.

The hydrohalogenation treatment of the PtRe/H-ZSM-5 catalyst has greatly enhanced the reactivity for CHE hydro- 


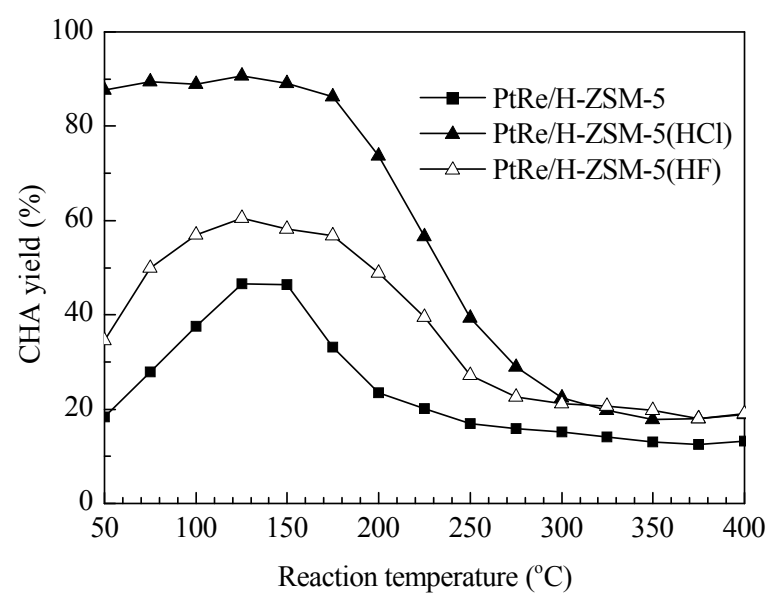

Fig. 3. Cyclohexane production using different catalysts.

genation. The $\mathrm{HCl}$ treatment had more effect than the $\mathrm{HF}$ treatment. Figure 3 shows that PtRe/H-ZSM-5 gave a maximum CHA production of $46.3 \%$ at $150{ }^{\circ} \mathrm{C}$, while PtRe/H-ZSM-5(HF) gave a maximum of $60.0 \%$ at $125{ }^{\circ} \mathrm{C}$, and $\mathrm{PtRe} / \mathrm{H}-\mathrm{ZSM}-5(\mathrm{HCl})$ exhibited the highest activity with $\sim 90 \%$ in the temperature range $50-175^{\circ} \mathrm{C}$. Beyond $175^{\circ} \mathrm{C}$, with a further increase of temperature, the hydrogenation activity declined since the reaction equilibrium was reversed from exothermic hydrogenation towards endothermic dehydrogenation. The enhancement of the hydrogenation activity with the HF treatment can be attributed to: (1) A better dispersion of PtRe bimetal in the support from $58.8 \%$ to $60.8 \%$ (Table 1); (2) A decrease in the basic Lewis sites present originally in the H-ZSM-5 zeolite via neutralization with HF; (3) A stronger "inductive effect" on the neighboring hydroxyl groups due to the influence of fluoride ions adsorbed on the surface of the H-ZSM-5 support [12].

On the other hand, HCl-treatment of PtRe/H-ZSM-5 changed the behavior of CHE hydrogenation (Fig. 3) such that CHA in the product significantly exceeded those obtained with the other two catalysts, particularly in the lower temperature region. This implied a significant activity enhancement of the PtRe bimetal on the surface of the PtRe/H-ZSM-5 $(\mathrm{HCl})$ catalyst. Previous studies by Aboul-Gheit [34,35] showed that benzene hydrogenation was completely inactive on a $0.6 \% \mathrm{Re} / \mathrm{Al}_{2} \mathrm{O}_{3}$ catalyst under high hydrogen pressure and temperatures of $100-140{ }^{\circ} \mathrm{C}$. This is evidence that $\mathrm{Re}$ by itself at a concentration of $\sim 0.6 \%$ cannot act as a hydrogenation component.

Recently, Aboul-Gheit et al. [36] doped unloaded $\mathrm{H}-\mathrm{ZSM}-5$ zeolite with $\mathrm{HCl}$ or $\mathrm{HF}$ and found that the acid site number, strength and hydrogenation activity on the $\mathrm{H}-\mathrm{ZSM}-5(\mathrm{HCl})$ and $\mathrm{H}-\mathrm{ZSM}-5(\mathrm{HF})$ catalysts were increased, and H-ZSM-5( $\mathrm{HCl})$ exhibited a significantly higher hydrogenation activity than H-ZSM-5(HF). This was attributed to a larger increase in the acid site number in the for- mer catalyst although the acid site strength was more enhanced in the HF-treated catalyst. In the present study, the loading of H-ZSM-5 zeolite with PtRe resulted in the same response towards $\mathrm{HCl}$ and $\mathrm{HF}$ treatments. Arena et al. [12] showed that the $\mathrm{Cl}^{-}$ion adsorbed on the surface of $\mathrm{Al}_{2} \mathrm{O}_{3}$ changes the electronic properties of the outer layer and decreases the basic Lewis sites. It also induces a stronger "inductive effect" on the neighboring hydroxyl groups on the zeolite surface, weakening the $\mathrm{O}-\mathrm{H}$ bond, and rendering the proton more acidic. Le Van Mao et al. [37] has doped H-ZSM-5 zeolite with a low concentration of $\mathrm{F}^{-}$species and found that its acidity was enhanced by forming new Brönsted acid sites, in addition to the strengthening of some acid sites of the parent zeolite.

Several authors have shown that acid sites in zeolites act as hydrogenation sites, particularly at higher temperatures. Sano et al. [38] reported that H-ZSM-5 zeolite becomes an active hydrogenating catalyst and it converts $95 \%$ of ethylene to ethane at a temperature of $535{ }^{\circ} \mathrm{C}$. Because no metal impurity in the zeolite was detected, Sano et al. concluded that the hydrogenation took place on the acidic sites of the zeolite. Jacobs and co-workers [39] also concluded that the Brönsted acid sites of zeolites act as active hydrogenation sites at higher temperatures. Senger et al. [40] have provided a deeper insight into this type of catalytic hydrogenation that proceeds without the participation of a transition metal.

The higher activity of the HCl-treated zeolite compared with the HF-treated one can be attributed to a physical effect rather than a chemical effect. The higher strength of HF than $\mathrm{HCl}$ allows it to attack $\mathrm{Si}$ in the zeolite, causing it to form debris of fluoro-silicon species that deposit in the channels of the zeolite that causes diffusion restriction that decreases the ability of CHA to diffuse and react.

\subsection{Isomerization of CHE to MCPEs and MCPA}

Figure 4 depicts the yield of methylcyclopentenes (MCPEs) as a function of reaction temperature. With the fluorinated and untreated catalysts, these olefinic isomers increased with temperature to reach a maximum, beyond which they decrease with a further increase of temperature. However, with the $\mathrm{HCl}$ treated catalyst, MCPEs increased slowly with temperature up to $400{ }^{\circ} \mathrm{C}$. The rates of formation of these isomers were in the order of PtRe/H-ZSM-5 > PtRe/H-ZSM-5(HF) > PtRe/H-ZSM-5(HCl). This order is the reverse of the order of the hydrogenation activities (Fig. $3)$. In other words, the yield of these MCPEs was higher with a less active hydrogenating catalyst and vice versa. Because these MCPEs are unsaturated isomers of CHE, they can be saturated to MCPA under the same reaction conditions. Hence, the more active hydrogenating catalysts will 


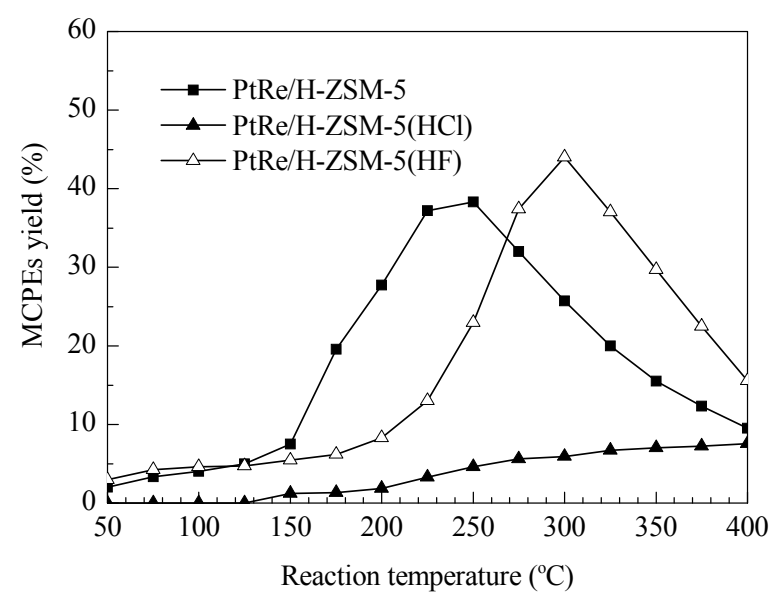

Fig. 4. MCPEs yield as a function of reaction temperature using different catalysts.

produce lower yields of MCPEs (Fig. 4). MCPEs products from the untreated and fluorinated catalysts were relatively high and reached their maxima $(38.3 \%$ and $44.0 \%$, respectively) at 250 and $300{ }^{\circ} \mathrm{C}$, respectively.

In the hydrogenation of MCPEs to MCPA (Fig. 5), the three unsaturated isomers (MCPEs) of CHE are saturated giving CHA isomer. The overall isomerization activities of the catalysts equal the sum of unsaturated and saturated C5-ring containing compounds, i.e., MCPEs + MCPA (Fig. 6). Dwyer et al. [41] defined the relative rates of isomerization (monomolecular reaction) and bimolecular hydrogen transfer as follows:

$$
\begin{gathered}
\text { Isomerization/Hydrogen transfer }= \\
I(\mathrm{MCPEs}+\mathrm{MCPA}) / I(\mathrm{CHA}+\mathrm{MCPA})
\end{gathered}
$$

where $I$ refers to the initial selectivity. Tjandra and Zaera [42] and Jolly et al. [43] have agreed with Dwyer et al., which indicates that the maximum of the isomerization from the six-membered ring to the five-membered one is not a critical catalyst specification. The reaction sequence in Eq.

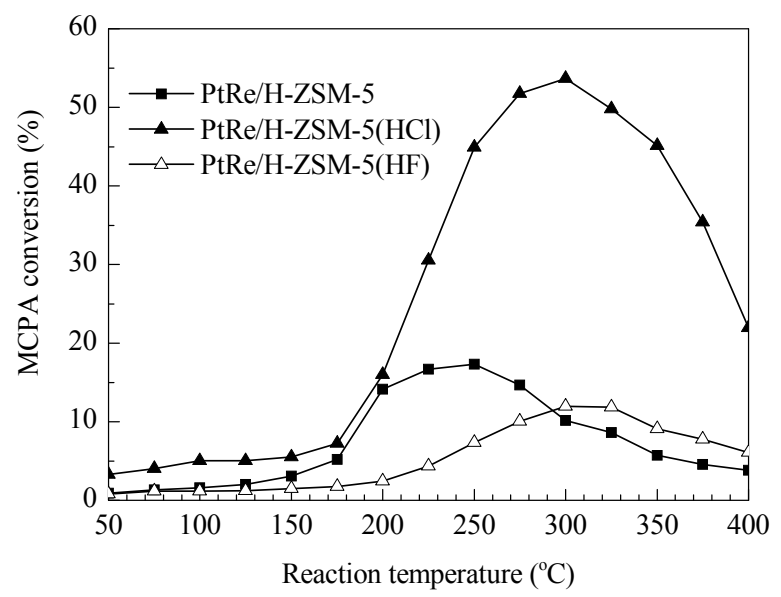

Fig. 5. MCPA conversion as a function of reaction temperature using different catalysts.

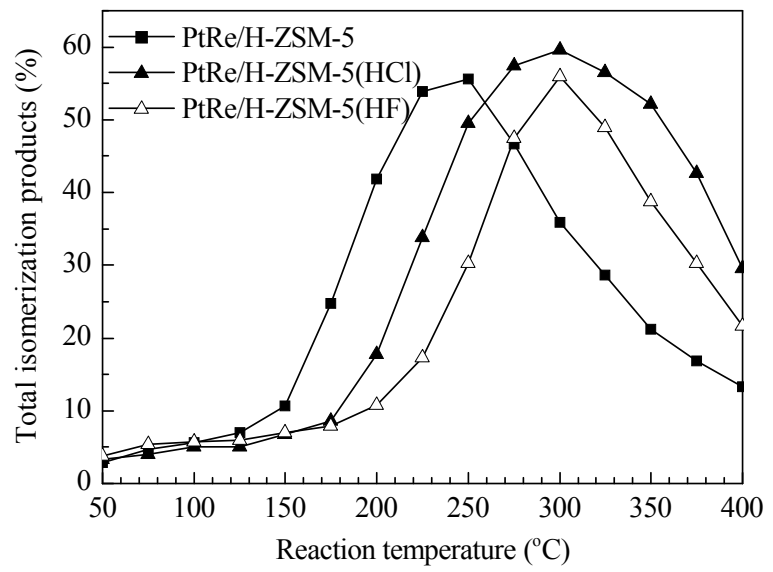

Fig. 6. Total isomerization products using different catalysts.

(1) shows that a molecule of CHE rearranges itself on an acid site to produce an equilibrium mixture of MCPEs, which are then hydrogenated on a PtRe site to produce a MCPA molecule.

Acid site $\quad \operatorname{PtRe}\left(+\mathrm{H}_{2}\right)$

cyclohexene $\longrightarrow$ methycyclopentenes $\longrightarrow$ methylcyclopentane (1)

Figure 5 shows that the hydrogenation activity of the PtRe/H-ZSM-5 $(\mathrm{HCl})$ catalyst greatly exceeds that of the HF-treated and untreated catalysts. The maximum conversion of MCPA was $53.6 \%$ at $300{ }^{\circ} \mathrm{C}$ on the PtRe/ H-ZSM-5 $(\mathrm{HCl})$ catalyst as compared with $11.9 \%$ and $17.3 \%$ on PtRe/H-ZSM-5(HF) and PtRe/H-ZSM-5 at 300 and 250 ${ }^{\circ} \mathrm{C}$, respectively. These results are in agreement with the results of the hydrogenation of CHE to CHA (Fig. 3), and both orders were the same as the order of acid site number and strength as well as the PtRe dispersion (Table 1). The effect of $\mathrm{Cl}^{-}$and $\mathrm{F}^{-}$ions in the catalysts in decreasing the basic Lewis sites, a stronger inductive effect on the neighboring $\mathrm{O}-\mathrm{H}$ bond, and rendering the proton more acidic should also contribute to these results.

\subsection{Dehydrogenation of CHE to CHDEs}

CHE first slowly dehydrogenates to a mixture of 1,3- and 1,4-CHDEs, then further dehydrogenates at higher rates with increasing temperature from 275 to $400{ }^{\circ} \mathrm{C}$, since dehydrogenation is endothermic (Fig. 7, Scheme 1). Land et al. [44] assumed that CHE at low temperatures is bonded to a noble metal substrate as di- $\sigma$ bonded CHE. This may undergo conversion analogous to olefin metathesis to form the bis-(alkylidene) and 1,6-hexadialkylidene. Furthermore, CHDEs dehydrogenate to benzene, which is the most stable dehydrogenation product.

Figure 7 shows the sum of 1,3- and 1,4-CHDEs in the product as a function of reaction temperature. With the untreated PtRe/H-ZSM-5 and PtRe/H-ZSM-5(HF) catalysts, 


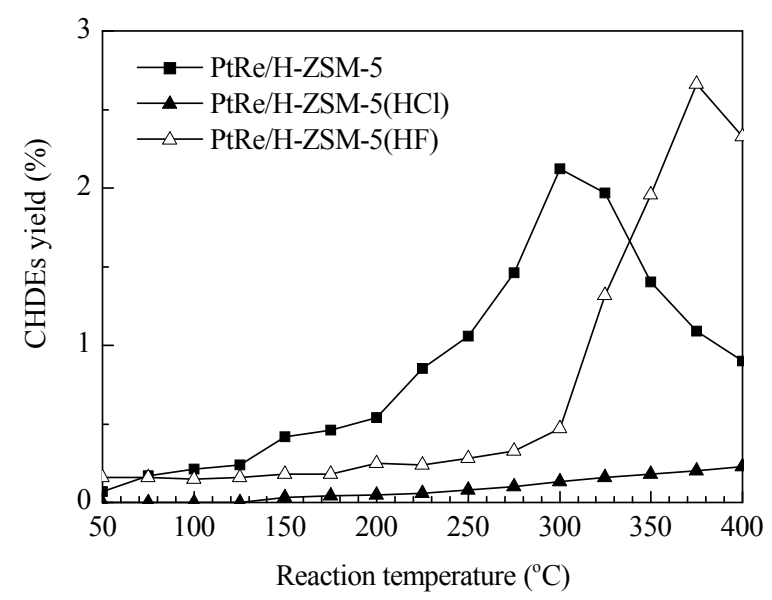

Fig. 7. Cyclohexadienes production using the PtRe/H-ZSM-5 catalysts.

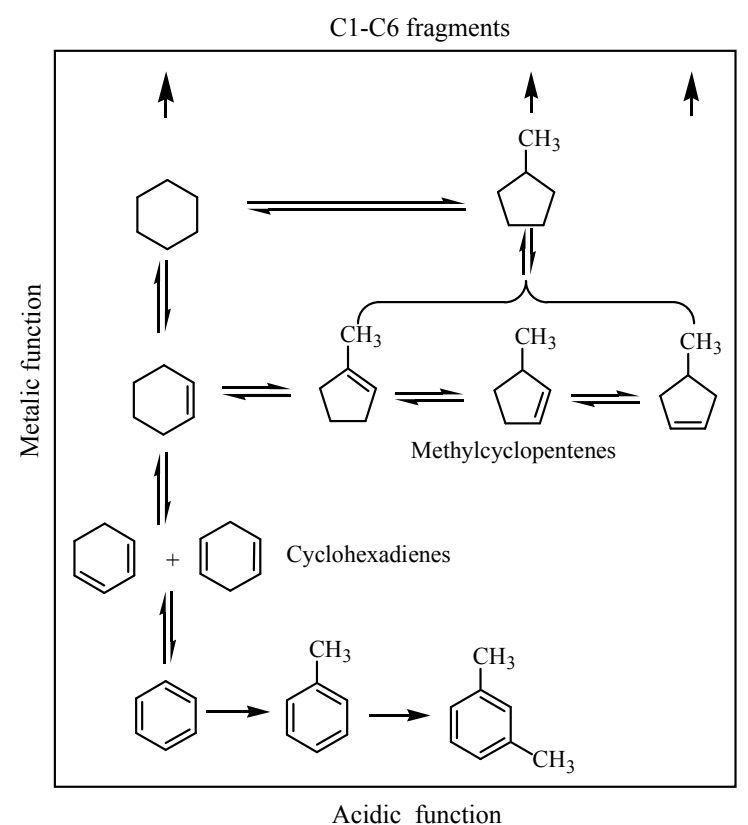

Scheme 1. Proposed scheme for cyclohexene hydroconversion.

the maximum CHDE amounts were $2.1 \%$, and $2.7 \%$ at 300 and $375{ }^{\circ} \mathrm{C}$, respectively. With the PtRe/H-ZSM-5(HCl) catalyst, the CHDEs increased gradually with temperature up to $0.23 \%$ at $400{ }^{\circ} \mathrm{C}$.

\subsection{Further dehydrogenation}

Dehydrogenation intermediates 1,3- and 1,4-CHDEs dehydrogenate further on Pt (111) to benzene. Su et al. [45] and Tsai et al. [46] found that CHE is converted to benzene on all Pt planes. Gland et al. [47] observed that CHE dehydrogenation on Pt (111) occur at some intermediate state before chemisorbed benzene is generated. CHDEs with different strengths of adsorption on the catalysts play a sig- nificant role in producing the ultimate products. More strongly adsorbed CHDEs retard aromatic formation. Peck and Koel [48] have assumed that the chemisorption of CHDEs on Pt (111) is irreversible and the chemisorbed monolayer dehydrogenates to form benzene upon heating. In the present work, the CHDEs reached maximum values of $0.23 \%-2.66 \%$ in the product (Fig. 7), which means that the CHDEs do not all remain chemisorbed on the metal surface till completely dehydrogenated to benzene. Figure 8 shows that the PtRe/H-ZSM-5 $(\mathrm{HCl})$ catalyst gave significantly more dehydrogenation products than the untreated and $\mathrm{HF}$ treated catalysts, particularly at the higher temperatures. At $400{ }^{\circ} \mathrm{C}$, the dehydrogenation products of $\mathrm{CHE}$ amounted to $21.46 \%$ using the chlorinated PtRe/H-ZSM-5 catalyst, while with the fluorinated catalyst, the total dehydrogenation products amounted to $9.78 \%$. This can be attributed to the higher diffusion restriction in case of the HF treated PtRe/H-ZSM-5, due to fluoro-aluminium debris deposition in the zeolite channels.

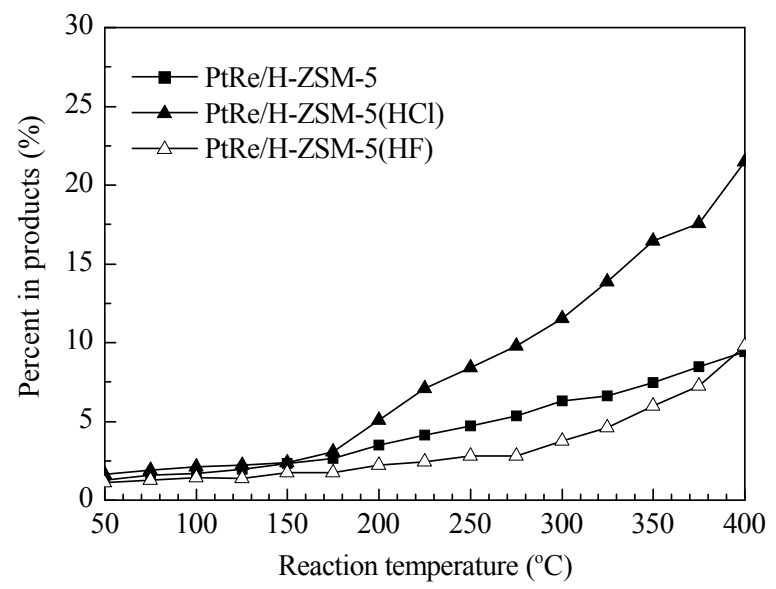

Fig. 8. Total dehydrogenation products using the PtRe/H-ZSM-5 catalysts.

\subsection{Benzene production}

Benzene is the most stable dehydrogenation product (final product), and hence a more active dehydrogenating catalyst will give a higher benzene production. Benzene production was low using the untreated and HF-treated catalysts (Fig. 9), and it was highest on the PtRe/H-ZSM-5 $(\mathrm{HCl})$ catalyst, it was $\sim 2.0$ at $50-150{ }^{\circ} \mathrm{C}$ and then increased continually beyond $150{ }^{\circ} \mathrm{C}$ to reach $15.3 \%$ at $400{ }^{\circ} \mathrm{C}$. However, on the PtRe/H-ZSM-5 and PtRe/H-ZSM-5(HF) catalysts, benzene production increased slowly with temperature up to $400{ }^{\circ} \mathrm{C}$. Benzene production on the catalysts was in the order of PtRe/H-ZSM-5 $(\mathrm{HCl})>$ PtRe/H-ZSM-5 $\geq$ PtRe/H-ZSM-5(HF). This is the order of acidic site strength distribution and PtRe dispersion in the catalysts. 


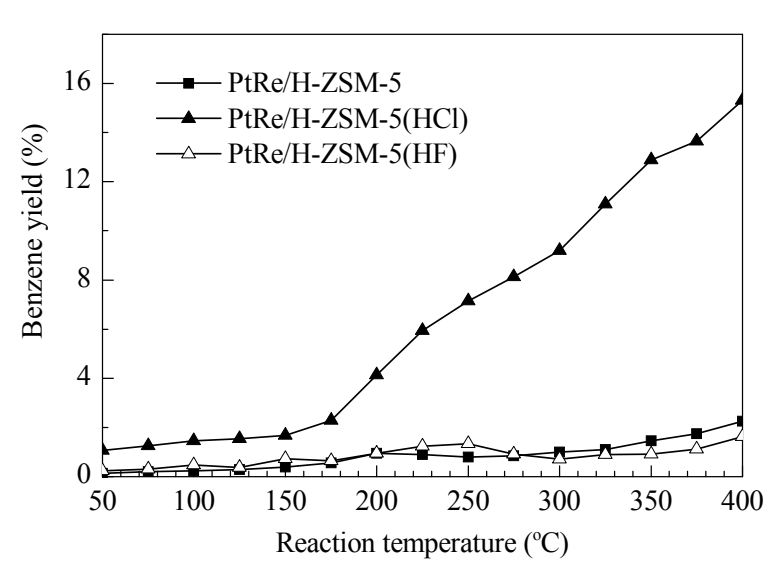

Fig. 9. Benzene yield using different catalysts.

\subsection{Alkylated products}

Benzene production was much higher on the PtRe/H-ZSM-5 $(\mathrm{HCl})$ catalyst (Fig. 9) than on the two other catalysts. However, toluene and xylenes (Figs. 10 and 11, respectively) were produced in lower quantities on this hydrochlorinated catalyst, indicating that more of the benzene

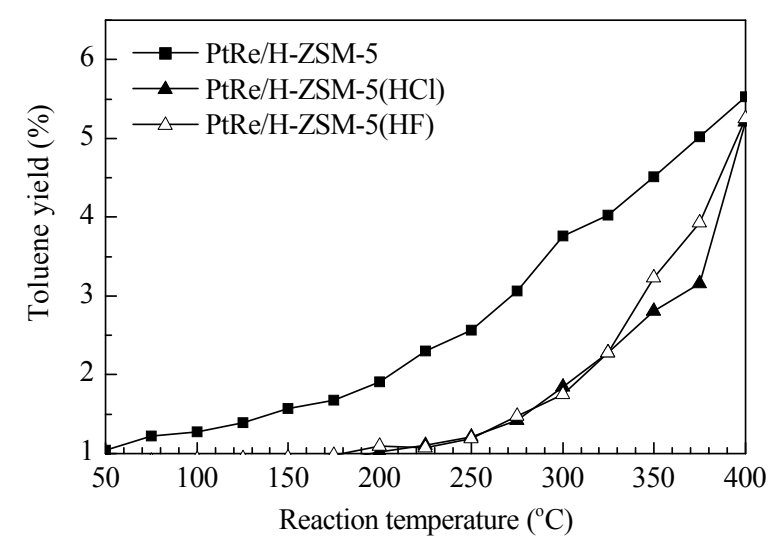

Fig. 10. Toluene in the product using the PtRe/H-ZSM-5 catalysts.

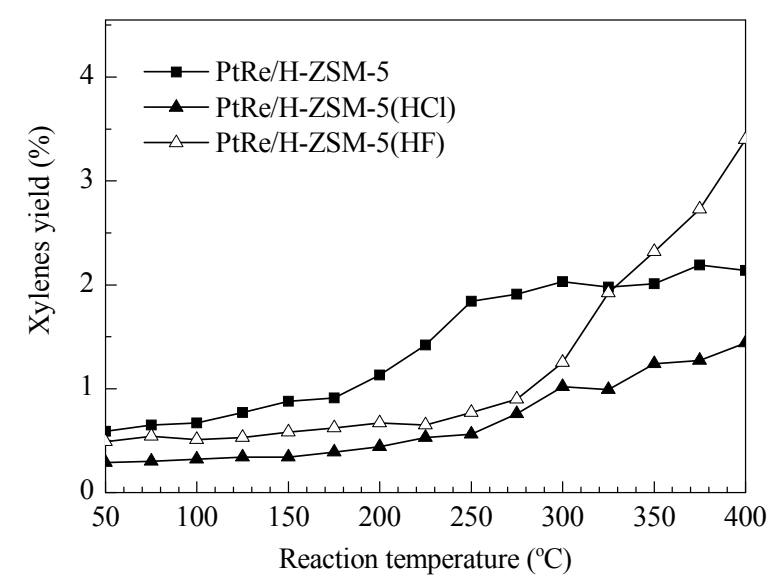

Fig. 11. Xylenes in the product using the PtRe/H-ZSM-5 catalysts. was produced during the alkylation (by methyl groups produced through cyclohexene hydrogenolysis).

The production of toluene and xylenes by alkylation is normally dependent on catalyst acidity. Nevertheless, these alkylaromatics were produced in larger amounts on the unhydrohalogenated catalyst, PtRe/H-ZSM-5. The catalysts treated with $\mathrm{HCl}$ or $\mathrm{HF}$ possessed lower alkylation activities, although their acidities were higher. This can be attributed to the absence of chloro- and/or fluoro-alumino species deposited in the pores of the PtRe/H-ZSM-5 catalyst.

\subsection{Hydrocracking reactions}

Traditionally, the cracking of a probe compound (cumene) is used to compare the strength of the acid sites in catalysts. However, in the present work, it is found that the bimetallic/zeolite catalyst (PtRe/H-ZSM-5) that was not treated with either $\mathrm{HCl}$ or $\mathrm{HF}$ gave the highest hydrocracking activity for cyclohexene. The catalysts were in the order of PtRe/H-ZSM-5 > PtRe/H-ZSM-5 (HF) > PtRe/ H-ZSM-5(HCl) (Fig. 12). In contrast, unloaded H-ZSM-5 gave the following order of hydrocracking activities of $\mathrm{H}-\mathrm{ZSM}-5(\mathrm{HF})>\mathrm{H}-\mathrm{ZSM}-5(\mathrm{HCl})>\mathrm{H}-\mathrm{ZSM}-5$ [36], which is the same order of the acid site strength. This correlation showed that the bimetal combination, PtRe, which is a conventional metal combination in commercial industrial hydroisomerization catalysts, has a significant influence on inhibiting the hydrocracking activity of the catalysts. However, in our previous work [49] using a monometallic catalyst (Pt/H-ZSM-5), the same effect of hydrochlorination and hydrofluorination on the hydrocracking of cyclohexene was observed as Pt/H-ZSM-5 > Pt/H-ZSM-5(HF) > $\mathrm{Pt} / \mathrm{H}-\mathrm{ZSM}-5(\mathrm{HCl})$. This indicates that the addition of Re to $\mathrm{Pt}$ in H-ZSM-5 zeolite results in a significant alteration of the hydrocracking activity. It is to be noted that the inhibition of CHE hydrocracking by hydrohalogenation with $\mathrm{HF}$ or $\mathrm{HCl}$ (particularly $\mathrm{HCl}$ ) is a favorable effect since this

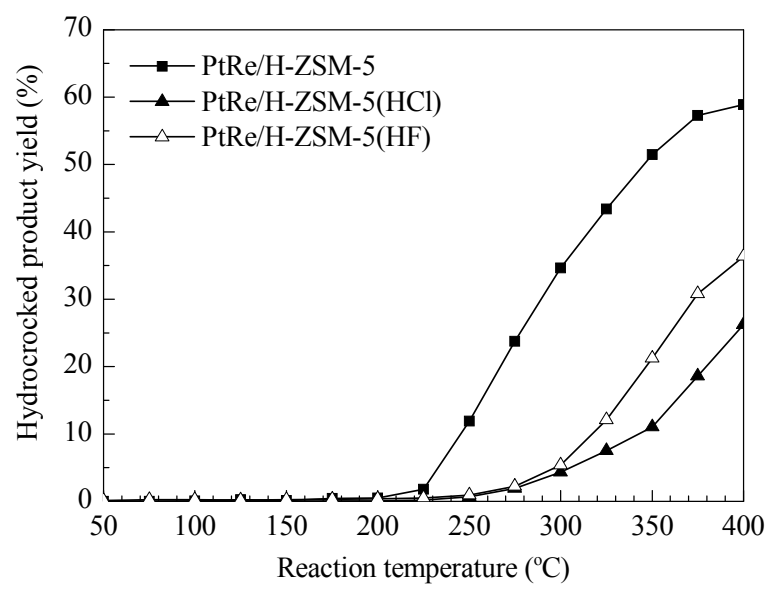

Fig. 12. Hydrocracked products using the PtRe/H-ZSM-5 catalysts. 
reaction causes a loss of the valuable hydrocarbon feedstock.

\section{Conclusions}

The hydroconversion of CHE was excellent and was highest in the whole temperature range with PtRe/H-ZSM-5(HCl). At lower temperatures, $\sim 90 \%$ of its activity was for the hydrogenation of $\mathrm{CHE}$ to $\mathrm{CHA}$. The activity was the lowest on the untreated catalyst due to its lowest PtRe dispersion, and lowest number and strength of acid sites. Dehydrogenation activity was also the highest on the hydrochlorinated catalyst. The lowest hydrocracking activity was attained with the hydrochlorinated catalyst, while the highest was attained with the untreated catalyst. This study exhibited the advantage of the $\mathrm{HCl}$ treated catalyst since hydrocracking is a loss of the hydrocarbon reactant.

\section{References}

1 Bartok M, Molnar A. Stereochemistry of Heterogeneous Metal Catalysis, 1985, 3: 53

2 Jacquinot E, Mendes A, Raatz F, Marcilly C, Ribeiro E, Caeiro J. Appl Catal A, 1990, 60: 101

3 Palinko I. Appl Catal A, 1995, 126: 39

$4 \mathrm{Xu}$ Z, Gates B C. J Catal, 1995, 154: 335

5 Rebhan D M, Haensel V. J Catal, 1988, 111: 397

6 Boudart M, McConica C M. J Catal, 1989, 117: 33

7 Blakely D W, Somorjai G A. J Catal, 1976, 42: 181

8 Davis S M, Somorjai G A. J Catal, 1990, 65: 78

9 Aboul-Fotouh S M, Aboul-Gheit A K. Appl Catal A, 2001, 208: 55

10 Ozimek B, Grezchowiak J, Radomski B, Szezyglowska G. React Kinet Catal Lett, 1981, 17: 139

11 Ozimek B, Radomski B. React Kinet Catal Lett, 1980, 15: 407

12 Arena F, Frusterl F, Mondeller N, Giordano N. J Chem Soc, Faraday Trans, 1992, 88: 3353

13 Ali A A, Ali L I, Aboul-Fotouh S M, Aboul-Gheit A K. Appl Catal A, 1998, 170: 285

14 Ali A A, Ali L I, Aboul-Fotouh S M, Aboul-Gheit A K. Appl Catal A, 2001, 215: 161

15 Ali L I, Ali A A, Aboul-Fotouh S M, Aboul-Gheit A K. Appl Catal A, 2001, 205: 129

16 Ali L I, Ali A A, Aboul-Fotouh S M, Aboul-Gheit A K. Appl Catal A, 1999, 177: 99

17 Kluksdahl H E. US 3415737. 1968
18 Biloen P, Helle J N, Verbeek H, Dautzenberg F M, Sachtler W M H. J Catal, 1980, 63: 112

19 Wagstaff N, Prins R. J Catal, 1979, 59: 434

20 Davis B H. J Catal, 1977, 46: 348

21 Okamoto Y, Ntitta Y, Imanaka T, Teranish S. J Catal, 1980, 64: 397

22 Davis S M, Somorjai G A. J Catal, 1980, 65: 78

23 Davis S M, Somorjai G A. Surf Sci, 1980, 91: 73

24 O'Rear D J, Löffler D G, Boudart M. J Catal, 1985, 94: 225

25 Gonzo E E, Boudart M. J Catal, 1978, 52: 462

26 DaCruz G M, Bulgi G, Djega-Mariadassou G D. Appl Catal, 1989, 46: 131

27 Ahmed K, Chowdhury H M. Chem Eng J, 1992, 50: 165

28 Ramirez J, Cuevas R, Agudo A L, Mendioroz S, Fierro J L G. Appl Catal, 1990, 57: 223

29 Aboul-Fotouh S M, Aboul-Gheit N A K, Hassan M M I. Chin J Catal, 2011, 32: 412

30 Aboul-Gheit N A K. J Chin Chem Soc, 2007, 54: 1211

31 Freel J. J Catal, 1972, 25: 139

32 Aboul-Gheit A K, Aboul-Gheit N A K, Awadallah A E. Chin J Catal, 2008, 29: 113

33 Aboul-Gheit A K, Aboul-Enein A A, Awadallah A E, Eman E A. Chin J Catal, 2010, 31: 1209

34 Aboul-Gheit A K, Cosyns J. J Appl Chem Biotechnol, 1976, 26: 15

35 Aboul-Gheit A K, Cosyns J. J Appl Chem Biotechnol, 1976, 26: 536

36 Aboul-Gheit A K, Aboul-Fotouh S M, Abdel-Hamid S M, Aboul-Gheit N A K. Appl Catal A, 2006, 297: 102

37 Le Van Mao R, Le T S, Fairbairn M, Muntasar A, Xiao S, Denes G. Appl Catal A, 1999, 185: 41

38 Sano T, Hagiwara H, Okabe K, Okado H, Saito K, Takaya H. Sekiyu Gakkaishi, 1986, 29: 89

39 Kanai J, Martens J A, Jacobs P A. J Catal, 1992, 133: 527

40 Senger S, Radom L. J Am Chem Soc, 2000, 122: 2613

41 Dwyer J, Dewing J, Karim K, Homes S, Fojo A, Garforth A A, Rawlence D J. Stud Surf Sci Catal, 1991, 69: 1

42 Tjandra S, Zaera F. J Catal, 1996, 164: 82

43 Jolly S, Saussey J, Lavalley J C. J Mol Catal, 1994, 86: 401

44 Land D P, Pettiett-Hall C L, Mclver R T, Hemminger J C. J Am Chem Soc, 1989, 111: 5970

$45 \mathrm{Su}$ X, Kung K Y, Lahtinen J, Shen Y R, Somorjai G A. J Mol Catal A, 1999, 141: 9

46 Tsai M C, Friend C M, Muetterties E L. J Am Chem Soc, 1982, 104: 2539

47 Gland J L, Baron K, Somorjai G A. J Catal, 1975, 36: 305

48 Peck J W, Koel B E. J Am Chem Soc, 1996, 118: 2708

49 Aboul-Gheit A K, Aboul-Fotouh S M, Abdel-Hamid S M, Aboul-Gheit N A K. Appl Catal A, 2006, 297: 102 